\title{
Simulations of the large-scale four point bending test using Rousselier model
}

DOI:

10.1016/j.engfracmech.2017.02.015

\section{Document Version}

Accepted author manuscript

Link to publication record in Manchester Research Explorer

\section{Citation for published version (APA):}

Arun, S., Sherry, A., Smith, M., \& Sheikh, M. (2017). Simulations of the large-scale four point bending test using Rousselier model. Engineering Fracture Mechanics, 178, 497-511.

https://doi.org/10.1016/j.engfracmech.2017.02.015

\section{Published in:}

Engineering Fracture Mechanics

\section{Citing this paper}

Please note that where the full-text provided on Manchester Research Explorer is the Author Accepted Manuscript or Proof version this may differ from the final Published version. If citing, it is advised that you check and use the publisher's definitive version.

\section{General rights}

Copyright and moral rights for the publications made accessible in the Research Explorer are retained by the authors and/or other copyright owners and it is a condition of accessing publications that users recognise and abide by the legal requirements associated with these rights.

\section{Takedown policy}

If you believe that this document breaches copyright please refer to the University of Manchester's Takedown Procedures [http://man.ac.uk/04Y6Bo] or contact uml.scholarlycommunications@manchester.ac.uk providing relevant details, so we can investigate your claim.

\section{OPEN ACCESS}




\title{
Simulations of the large-scale four point bending test using Rousselier model
}

\author{
Sutham Arun \\ School of Engineering \\ University of Phayao \\ Phayao, Thailand \\ Email: sutham.arun@gmail.com \\ Andrew H Sherry

$\begin{array}{cc}\text { School of Materials } & \text { National Nuclear Laboratory } \\ \text { The University of Manchester } & \text { Warrington, UK } \\ \text { Manchester, UK } & \text { Email: andrew.h.sherry@nnl.co.uk }\end{array}$ \\ Mike C Smith \\ School of Mechanical, Aerospace \& Civil Engineering \\ The University of Manchester \\ Manchester, UK \\ Email: mike.c.smith@manchester.ac.uk \\ Mohammad Sheikh \\ School of Mechanical, Aerospace \& Civil Engineering \\ The University of Manchester \\ Manchester, UK \\ Email: mohammad.a.sheikh@manchester.ac.uk
}

\begin{abstract}
STYLE or "Structural integrity for lifetime management-non-RPV component" was a EURATOM Framework 7 project which try to develop a new understanding of the combined influence of mechanical loading and residual stresses on the ductile fracture behaviour. The project was divided into two main parts, i.e. experimental part and the simulation part. The work presented in this paper relates to the simulation part of the STYLE project. The paper presents the results of a ductile damage mechanics procedure that was developed to predict ductile crack extension under a combination of primary and weld residual stress in a large-scale four-point bending test performed on a repair welded Esshete 1250 pipe containing a circumferential through-thickness crack. In this work, a finite element model of the test was created in ABAQUS, and the weld residual stress was introduced to the model by an iterative technique. The Rousselier model was calibrated against the ductile fracture behaviour of a test specimen including crack initiation and growth. The prediction of final crack growth in the large-scale test obtained from this analysis is compared with the results obtained from a fracture mechanics analysis based on the $J$-integral and the large-scale test outcome. The Rousselier model and the fracture mechanics approach predicted a similar amount of ductile tearing to the average amount of crack extension observed in the large-scale test, with any slight differences likely to be an artefact of either non-symmetric loading in the test, or differences between test weld residual stresses or material properties compared with those measured on "sister" specimens. The shape of the crack growth was well predicted by both approaches.
\end{abstract}




\section{Introduction}

It is well known that the residual stresses, which arise in welded joints due to strains caused by solidification, phase change and contraction during welding, have a significant influence on failure behaviour of engineering structures. Residual stresses can combine with service stresses to increases the potential for crack initiation and lead to higher rates of growth of defects, or even initiate cracking before a component is subjected to service loads [1-3]. The study carried out by Ren et al. [4] confirms that the residual stress can significantly elevate the crack-tip constraint which results in an increase of the probability of cleavage fracture in ferritic steels. In addition, a tensile residual stress can significantly reduce the apparent ductile crack growth resistance when the crack growth is small [5]. It is, therefore, necessary to study the effect of residual stress on various aspects of failure in order to perform accurate and reliable structural integrity assessments.

As the residual stress fields containing in welded components are always complex in form, validated methods for predicting the failure behaviour of welded structures, particularly if nonstress relieved, are desirable. At present, finite element (FE) analysis is widely accepted as a popular tool for the prediction of defect behaviour in engineering component. Accordingly, residual stresses can be introduced into the analysis via two main methods. The first method is to introduce the residual stress via plastic deformation which requires a knowledge of the history of the prior deformation in the structure. A second method is to specify the residual stress directly at the integration points of the model as an initial stress. This method requires a definition of the stress field in the initial condition of the structure.

The prediction of failure in large-scale structures is required by a number of industries including the oil and gas, nuclear and aerospace, and a number of fracture mechanics approaches have been developed to do so, including API 579-1/ASME FFS-1 which sets out a number of fitness for service procedures used in the oil and gas, petrochemical and chemical industries [6], and BS7910 [7]. In the nuclear sector, the R6 defect assessment procedure is widely used [8].

These approaches tend to use the principles of fracture mechanics which provide a conservative approach to the prediction of failure, particularly where defect loading includes a component of residual stress, e.g. due to welding. For example, Lei et al. [9] demonstrated the conservatism of BS7910 for assessing several types of defect in girth welds. Similarly, Swankie et al. [10].

The conservatism in fracture mechanics-based assessments of pipes containing defects has led to the assessment of damage mechanics approaches for the prediction of ductile failure in pipes [11], applied the Gurson-Tvergaard-Needleman (GTN) model [12-13] to predict the behaviour of a number of external circumferential pipe defects loaded by a combination of internal pressure and remote bending. The results demonstrated that the GTN damage mechanics model, calibrated against single edge cracked tension (SENT) fracture toughness results, was able to predict crack initiation and growth in the tests. This work has been extended to assess the influence of weld residual stresses on ductile fracture in SENT specimens [14]. For this geometry, residual stresses were found to have little influence on fracture strength. 
The work presented in this paper builds on these studies to assess the ability of a ductile damage mechanics approach to predict crack growth in a pipe weld containing a non-stress relieved weld repair. This extends these previous studies to incorporate not only primary loading, but also high and non-uniform weld residual stresses in a structural pipe geometry. The resulting simulation was part of the STYLE project [15]. It aims to present a finite element and damage mechanics approach which can used to assess failure in welded components. The central focus of this paper is to describe the ductile fracture behaviour of a large scale bending test conducted at CEA as part of EU-STYLE [16]. The test was carried on a repair-welded pipe that contained a circumferential through-thickness crack. The test specimen, called Mock-Up 2 (MU2), was manufactured from two Esshete 1250 stainless steel pips joined by a girth weld. The weld contained a short, deep weld repair and a through thickness pre-crack that was inserted at the centre of the repair. Before testing, both ends of the MU2 test piece were welded to extension arms created from 304L stainless steel to provide bending span. The main section of MU2 and the pre-crack position are shown schematically in Figs. 1 and 2. More details of this experiment had been already explained in Section 2.

In this work, the FE model of the MU2-test was created in ABAQUS, and the weld residual stress fields were introduced into the welding section of the model as initial stress by using iterative technique [17]. The Rousselier model was employed to predict the failure behaviour, such as crack initiation position and load, crack propagation profiles and final crack growth, of a circumferential through-thickness pre crack in welding zone. The results obtain from this simulation were compared with the results obtained from a prediction that employed fracture mechanics based on the $J$-integral and from the test outcome itself.

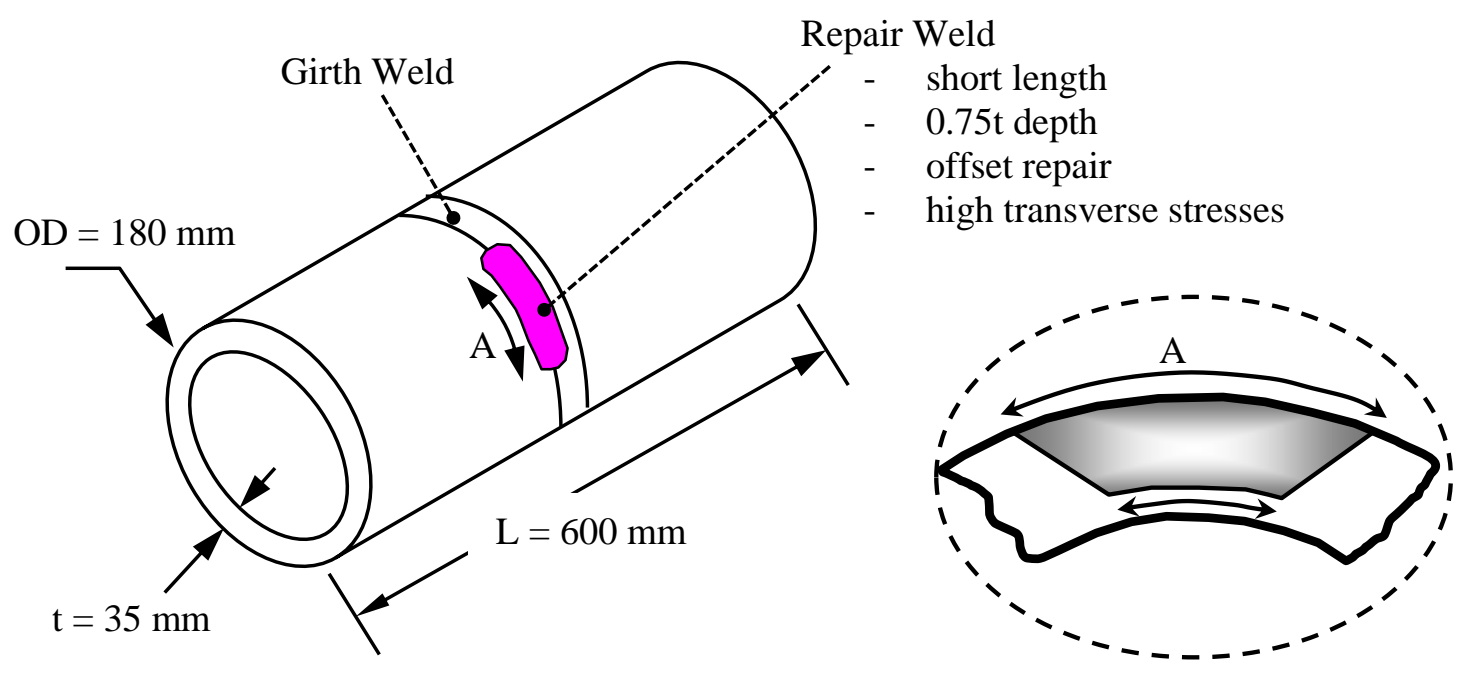

Fig. 1 Schematic of MU2-pipe. 

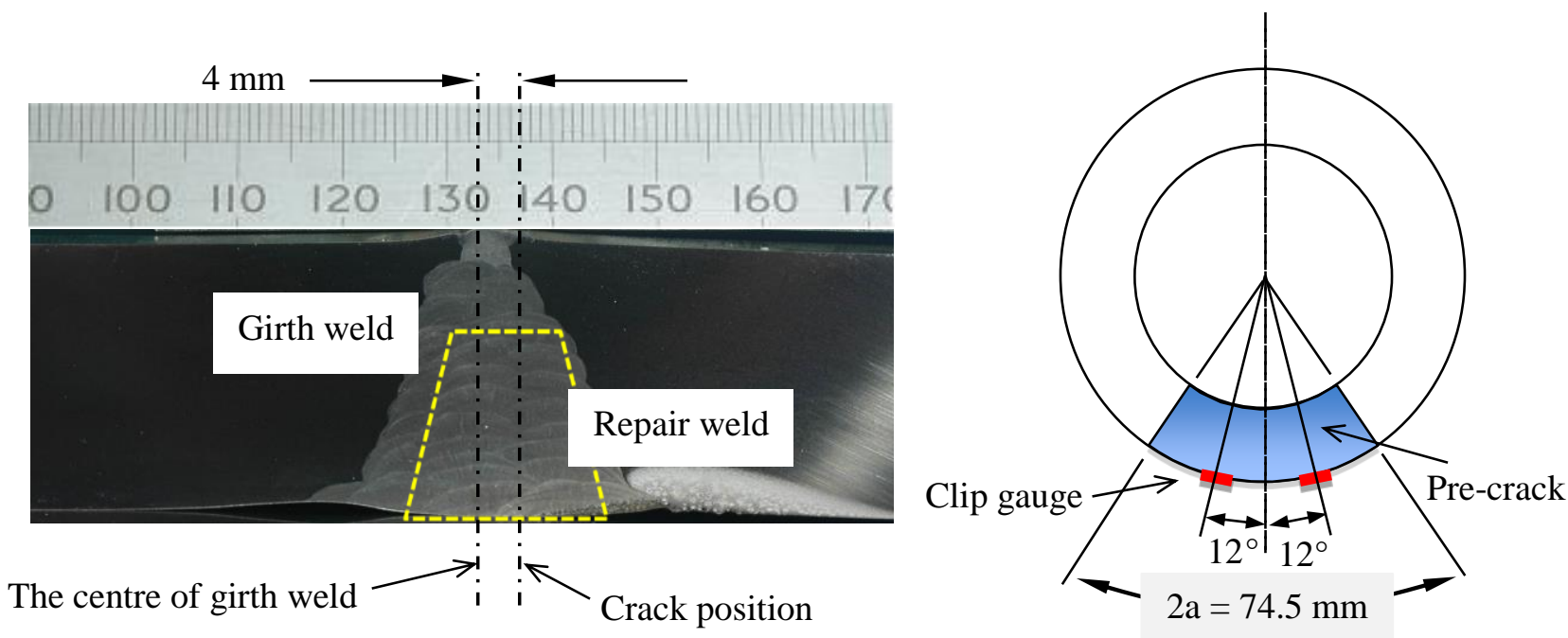

$\left(47^{\circ}\right)$

Fig. 2 Dimensions of the through thickness pre-crack and clip gauge position.

\section{The large scale four-point bending test (the MU2-test)}

A number of "sister" pipe weld specimens were prepared; one for the large-scale test and the others for material property and residual stress measurements. Figure 3 illustrates the experimental set-up of the large-scale MU2-test which was divided into two main phases [16]. The first phase was the fatigue pre-cracking which developed a straight fronted pre-crack shown in Fig. 2. In this phase, an EDM notch (Fig. 4) was introduced into the middle plane of the repair weld. As there were high tensile residual stresses in weld, the MU2 specimen was pre-cracked upside down with the EDM notch located on the top of the pipe and the precracking was done in compression. Therefore, compressive fatigue loading reduced the residual stress-induce stress intensity factor at the crack-tip. The test specimen was subjected to compressive fatigue cycles until the sharp pre-crack was generated from the EDM notch.

The second phase was the ductile tearing test. In this phase, the test specimen was subjected to monotonic loading to promote ductile crack growth from the initial fatigue pre-crack. The pipe was subjected to a number of unloads with the unsuccessful aim of marking the extent of ductile crack growth on the fracture surfaces. During the test, two clip gauges were attached at the outer pipe surface of the slot in order to measure the values of crack mouth opening displacement (CMOD), Fig. 2.

Figure 4 shows the optical examination of the fracture surface after the test. It can be seen that the sharp pre-crack generated during Phase I were not completely symmetrical. On the outer surface of the pipe, the pre-crack had a length of about $5 \mathrm{~mm}$ at the north and about $8 \mathrm{~mm}$ at the south respectively. The crack extension generated from ductile tearing test was also not symmetrical. The maximum extent of crack growth was about 2.0-2.5 $\mathrm{mm}$ in south location and about $3 \mathrm{~mm}$ in north location. This happened after the test specimen was subjected to the maximum load of $213.1 \mathrm{kN}$ at the end of the test. In this state, the value of CMOD measured from the test was about $2.5 \mathrm{~mm}$. 


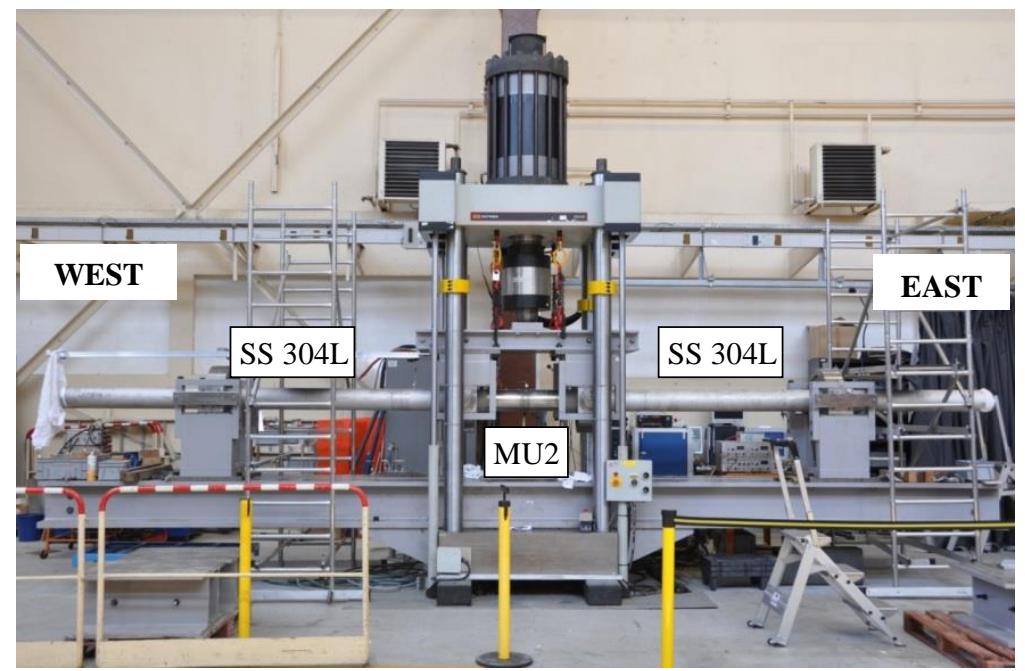

(a)

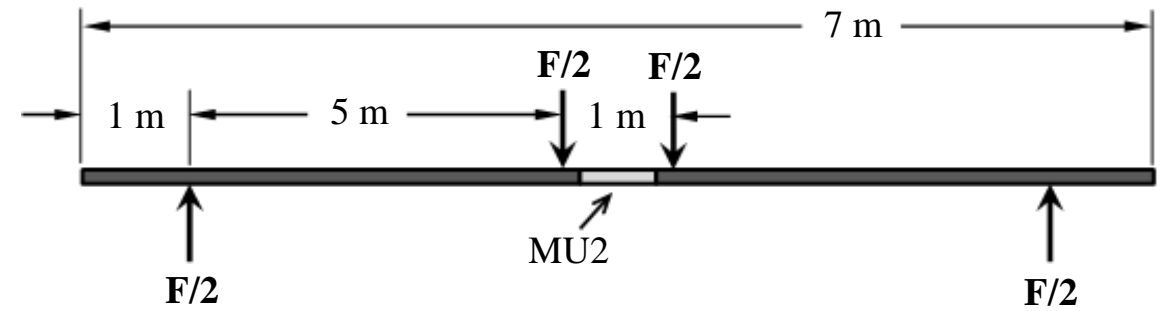

(b)

Fig. 3 (a) Set up for the large-scale four point bend experiment (view of south side of the pipe), and (b) loading arrangement for the experiment [16].

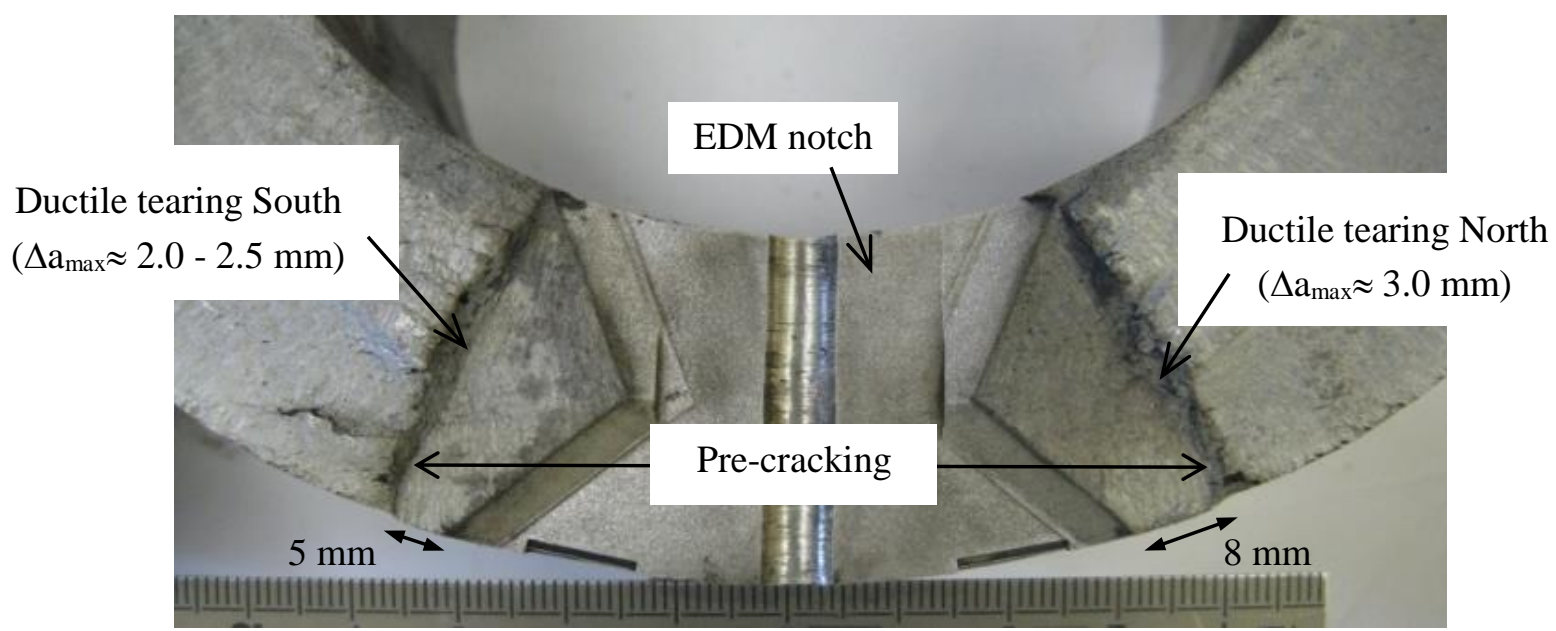

Fig. 4 Post-test crack surface. 


\section{Material properties for FE simulation}

The MU2-test was supported by a set of standard tensile and ductile fracture tests performed on a similar welded pipe in order to provide the material data that are necessary in a full structural integrity assessment and FE analysis. These specimens were extracted from the weld material in the "sister" welded Esshete stainless steel pipe which was welded under identical conditions as that used for MU2, but without the repair weld. For the tensile test, the extracted specimens were oriented in the axial direction with respect to the pipe. For ductile fracture toughness tests, the specimens were extracted with the crack plane located at the weld centreline. These specimens were oriented with the loading direction parallel to the axial direction and crack growth direction in the circumferential direction of the pipe.

\subsection{Material tensile properties}

Figure 5. presents true stress true strain curves for the Esshete parent and weld materials. The curves were derived from the load-displacement curves of the tensile tests performed by EDF Energy [18-20]. The linear section of these curves was used to estimate the elastic modulus for Esshete parent and weld materials. This process was performed in a spreadsheet and provided the values of elastic modulus for Esshete parent and weld materials of $204.5 \mathrm{GPa}$ and $158 \mathrm{GPa}$ respectively.

The tensile properties for 304L extension pieces and extension weld material were not available at the time of doing STYLE project. The material properties for 316L were therefore used instead. A report published by the Idaho National Laboratory [21] showed that the room temperature tensile properties of $316 \mathrm{~L}$ and $304 \mathrm{~L}$ are quite close. Young's modulus for $316 \mathrm{~L}$ parent and weld were taken as 195.6 GPa and 171.0 GPa, with Poisson's ratio of 0.294. The 316L tensile properties assigned to the $304 \mathrm{~L}$ parent and weld metals are included in Fig 5.

\subsection{Crack resistance curve for the Esshete weld metal}

The fracture toughness tests were carried out on standard $25 \mathrm{~mm}$-thick compact tension (CT) specimens, with $20 \%$ side grooves. The test were performed by EDF Energy at room temperature using the unloading compliance method [22-23]. The test data were subsequently used to establish the crack growth resistance curve for Esshete weld metal as shown in Fig. 6. 


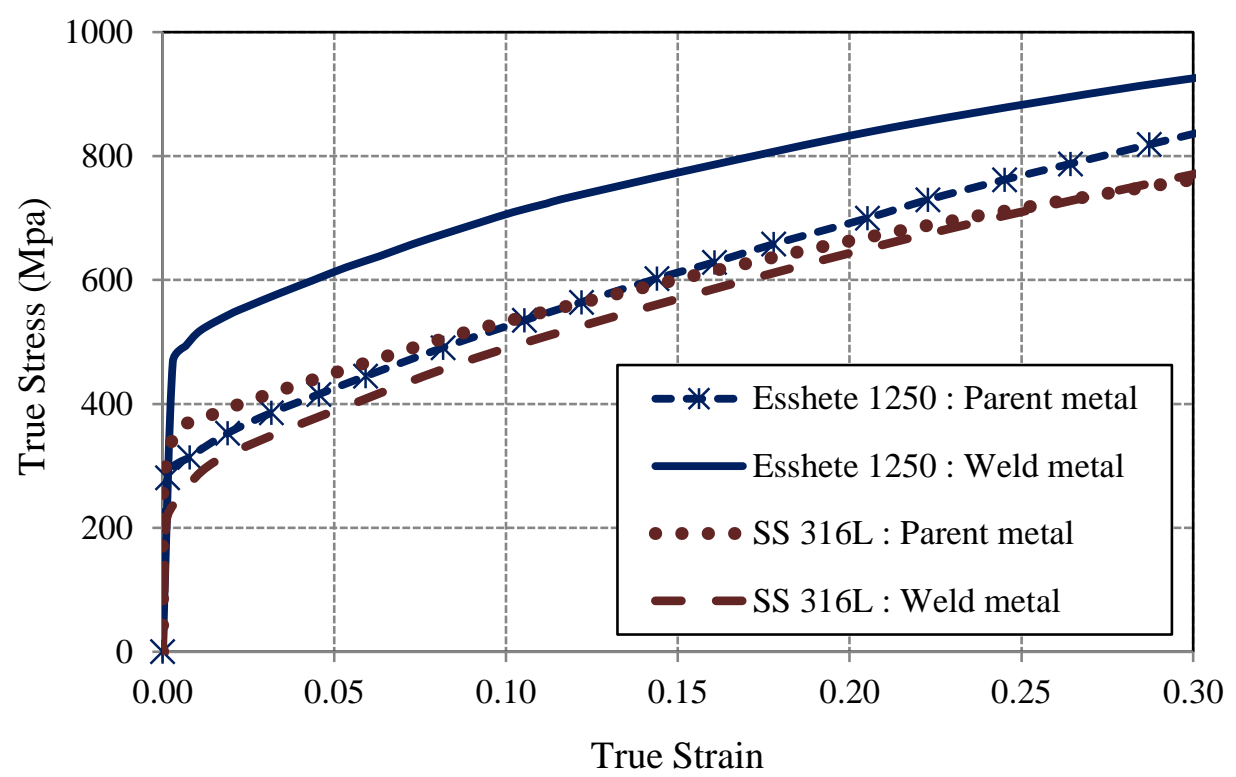

Fig. 5 Stress-Strain data for Esshete 1250 and SS316L materials.

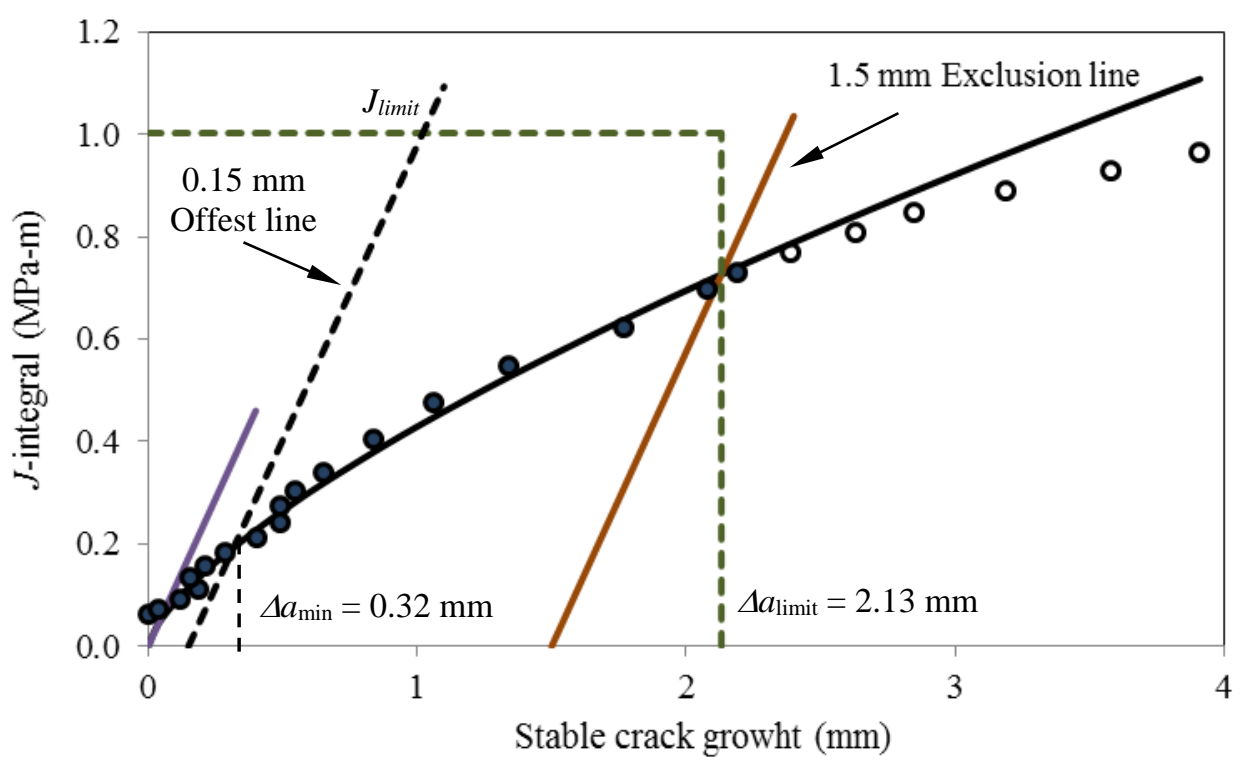

FIG. 6 Crack resistance curve for the Esshete weld metal. 


\section{The Rousselier model}

The Rousselier model is one of a pressure-dependent plasticity models [24] which defines the softening of material by the accumulation of damage parameter. The yield function of this model is developed from a plastic potential function and von-Mises criterion, with the associated normality rule. According to this, the yield function takes the form [25-26]:

$$
\Phi=\frac{q}{\rho}-R\left(\epsilon_{e q}\right)+D f \sigma_{1} \exp \left(\frac{-p}{\rho \sigma_{1}}\right)=0
$$

where $q$ is the von Mises equivalent stress, $p$ is pressure or hydrostatic stress, the parameter $\rho=(1-f) /\left(1-f_{0}\right)$ is the relative density, $f$ is the damage variable or void

volume fraction, $f_{0}$ is the initial void volume fraction in the material, $R\left(\epsilon_{e q}\right)$ is the hardening function of the material, $\epsilon_{e q}$ is the equivalent plastic strain, $D$ and $\sigma_{1}$ are the Rousselier constants.

The accuracy of failure prediction by using Rousselier model depends on the precision of the model parameters required in the model. These are $f_{0}, D$ and $\sigma_{1}$ respectively. The Rousselier model used in this work was applied in the context of a local formulation in which the values of $f$ depends exclusively on the stress and strain at the material point of interested. Therefore, when the model is implemented in the FE analysis, the computation will exhibit a meshdependence where stress and strain gradients are present such as at the tip of a notch or crack. According to this, the element size, $L_{c}$, is introduced as an additional material parameter for the model. Many authors suggested to couple the mesh size directly to the mean distance between the inclusions leading to the primary voids [25, 27].

In this work, the Rousselier model was implemented via an ABAQUS [28] user defined subroutine (VUMAT) by using the algorithms of Aravas [24]. The numerical algorithm and the validation of this subroutine were presented in [29]. This subroutine was used in the prediction of crack initiation and growth in MU2-test.

\section{The determination of Rousselier parameters for Esshete weld metal}

Rousselier parameters, i.e, $f_{0}, D, \sigma_{1}$ and $L_{c}$, for Esshete weld metal were calibrated by following the method explained in $[8,25-26,30]$. The values of $f_{0}$ was first estimated from the chemical composition of Esshete weld metal [20] by using Franklin's formula [31]. The value of $D$ was taken to be equal to 2 as suggested in $[26,30]$. The remaining parameters $\sigma_{1}$ and $L_{c}$ in the constitutive equation were calibrated via the FE model of the CT specimen, with $20 \%$ side grooves. This model was created in ABAQUS/Explicit with the implementation of VUMAT for Rousselier model. The process of calibration was performed by fitting the relationship between the values of the $J$-integral and the crack growth $(\Delta a)$ obtained from FE analysis with the crack resistance curve. Details of the parameter calibration have been clearly explained in [32]. The Rousselier parameters for Esshete weld metal have been summarized in Table 1 . These parameters are subsequently used to predict crack initiation and growth in MU2 test. 
Table 1 Values of Rousselier parameters calibrated for the Esshete weld material [32].

\begin{tabular}{|c|c|}
\hline Rousselier parameter & Calibrated Value \\
\hline The initial void volume fraction, $f_{0}$ & 0.0004 \\
\hline Material parameter $D$ & 2.0 \\
\hline Material parameter $\sigma_{1}$ & $506 \mathrm{MPa}$ \\
\hline Crack tip element size, $L_{c}$ & $50 \mu \mathrm{m}$ \\
\hline
\end{tabular}

\section{The FE analysis of MU2 test}

The three dimensional FE model of MU2-test was developed in ABAQUS by using the submodelling technique. This technique enables the user to study of the area of interest in detail by modelling the important section of the model in sufficient detail, i.e. using a submodel or truncated model. Using the submodelling technique in ABAQUS involved two main steps. The first step was to create and analyse the FE model of the full structure : the global model. This model was created using a relatively coarse mesh and possibly a simplified geometry. Once the global model was analysed, the truncated FE model representing the critical section of the structure was created and analysed by prescribing boundary conditions derived from the global model.

\subsection{The global FE model of MU2-test}

The global model was created according to the experimental set-up shown in Fig. 3. This model composed of the full test specimen and four mounting rings as shown in Fig. 7. The full test specimen which compose of the MU2 test section, the two 304L extension pieces and welding zones was created as a single part using continuum elements of ABAQUS type C3D8R. Due to symmetry, only one half of the test specimen was modelled with symmetry boundary conditions applied to the symmetry surface.

The mounting rings were created using 3D discrete rigid shells of revolution. They were positioned on the test specimen at the same place as the loading points and support points of the experiment, Fig 3. The supporting point rings were fully constrained, with the exception of rotation about the z-axis. The same constraints were also applied to the loading point rigs but with an applied downward vertical displacement. The contact between the test specimen and the mounting rings was modelled by using the finite sliding surface-to-surface contact with frictionless tangential behaviour and hard contact normal behaviour. 


\subsection{The truncated model}

The truncated model represented the middle section of the MU2 test specimen and contained both Esshete parent and weld materials. The displacement fields obtained from the FE analysis of the global model of MU2 test were prescribed to both end surfaces of the truncated model. This process was followed by using the submodelling technique available in the boundary condition module in ABAQUS. The other constraint applied was to prevent movement in the axial direction by fixing a single point on the outside surface of the model, opposite the crack location.

Like the global model, the truncated model made up of eight-noded reduced integration elements $(C 3 D 8 R)$. As the mesh size in the region ahead of the crack front must be regular, partitions were created on the crack plane in order to generate a dense mesh around the crack front. This ensured that crack extension was modelling in equal increment of $L_{c}$ across the full width of crack. The geometry of the truncated FE model and the partitions on the crack plane are shown in Fig. 8.

In the construction of the truncated FE model of MU2-test, the uniform square-section mesh size of $L_{c}=50 \mu \mathrm{m}$ was required in the region ahead of the crack front to represent the average critical interparticle spacing. This element size was very small compared to the thickness of the MU2 pipe $(35 \mathrm{~mm})$ and hence affected the overall number of elements required for the model. With this element size, 700 elements were needed through the pipe thickness with more than 3,000,000 elements required for the entire truncated model.

In order to reduce the number of elements in the vicinity of the crack tip, the dimension of elements parallel to the crack front, and within the plane strain region of the specimen where the stress state was uniform, was increased from $50 \mu \mathrm{m}$ to $200 \mu \mathrm{m}$. The dimension of elements towards the inner and outer edge of the pipe, where plane stress conditions dominiate, and in the crack growth direction was maintained as $50 \mu \mathrm{m}$. A total of 70 element slices were generated through the pipe thickness in the crack plane. This generated a total of 608,000 elements within the model, Fig. 8.

\subsection{Verification and validation of the model}

Loading and boundary conditions of FE model of MU2-test were verified by running the model with elastic material property only. The results of interest from running this model is the variation in the stress intensity factor, $K_{I}$, along the crack front at a given applied load with respect to the distance from the pipe inner surface. This results were compared with a standard solution provided in R6 procedure [8]:

$$
K_{I}=\left\{\sigma_{m} G_{1}+\sigma_{b}\left(G_{1}-2 G_{2}\right)+\sigma_{g b} G_{3}\right\} \sqrt{\pi a}
$$

where $\sigma_{g b}$ is the maximum bending stress of uncrack cylinder. $\sigma_{m}$ and $\sigma_{b}$ are the uniform membrane stress and the through wall bending stress (assumed to be zero for this case). $G_{1}, G_{2}$ and $G_{3}$ are the influence coefficients depending on crack size and pipe geometry.

Figure 9 shows that the elastic FE-results agreed to within a few percent of Eq. (2) except at the edge of the crack front close to the outer surface of the cylinder where the FE model 
predicted a decrease in $K_{I}$, probably due to the transition from a plane strain to a plane stress condition.
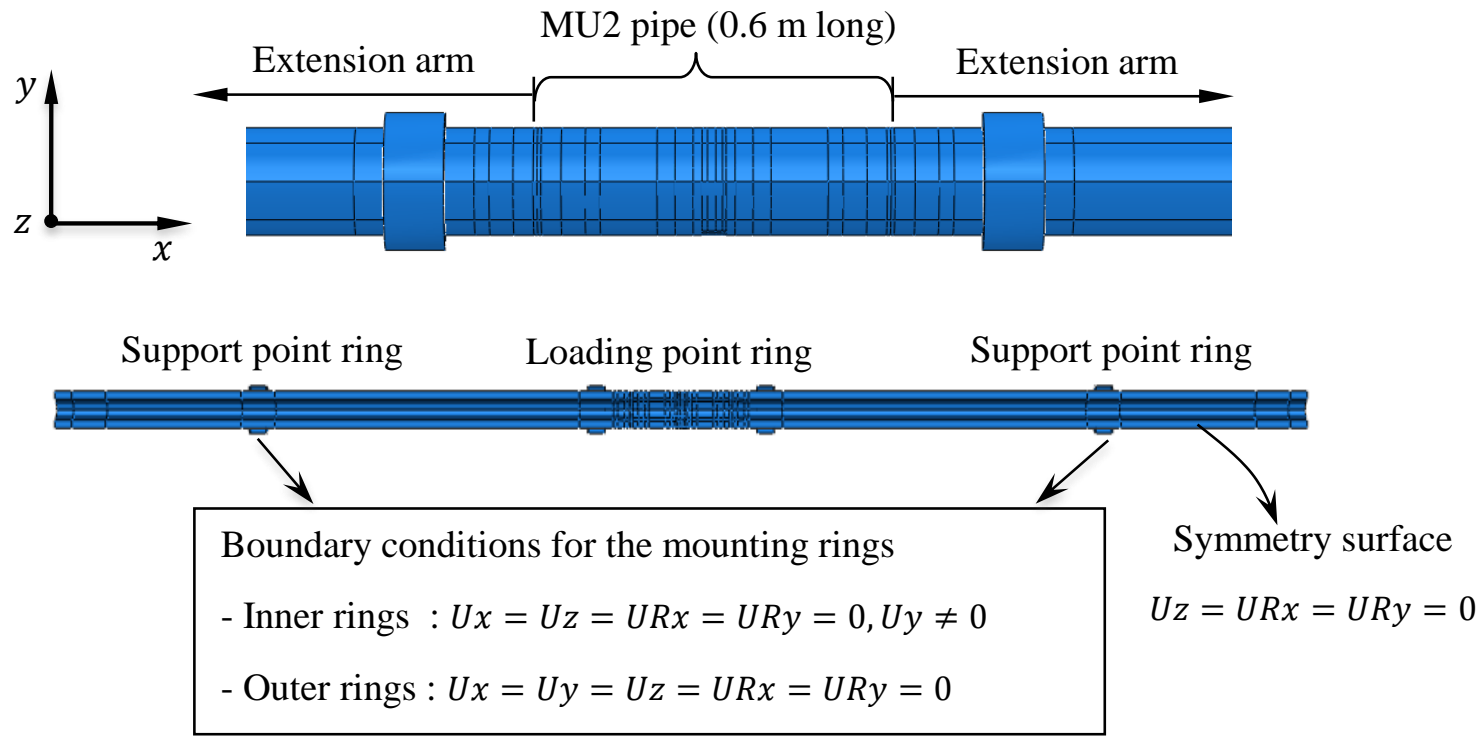

Fig. 7 Assembly of the full test specimen and mounting rings in the global model. 


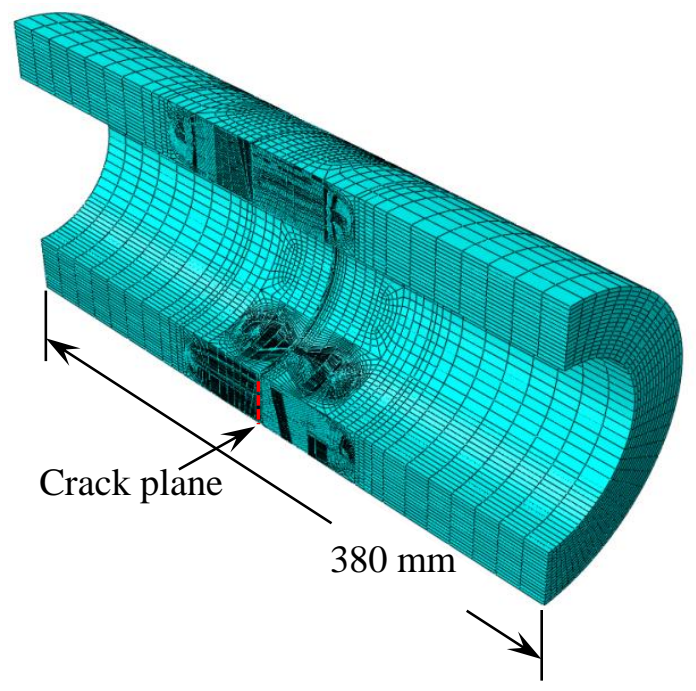

(a)

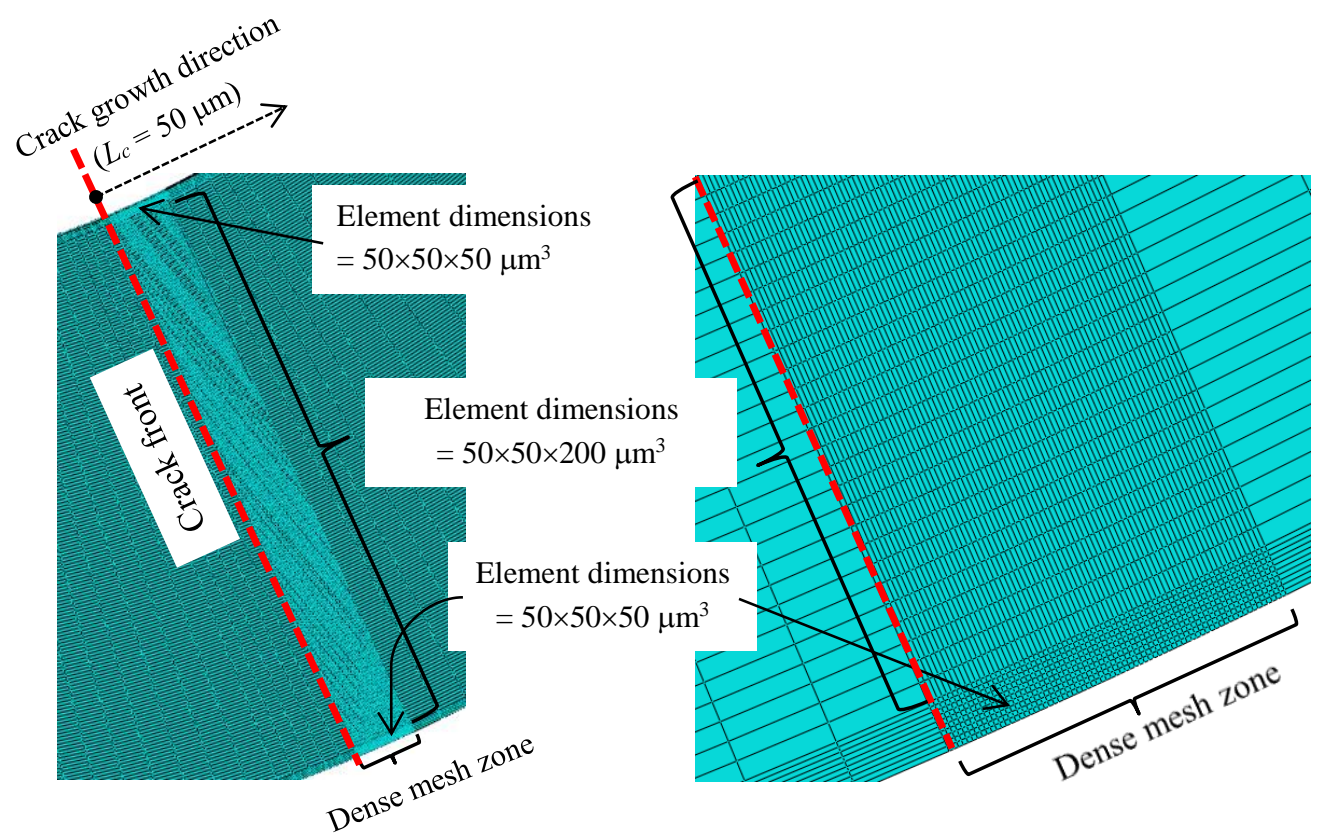

(b)

Fig. 8 (a) FE mesh overview and (b) FE mesh generated on the crack plane for the truncated model of MU2 specimen. 


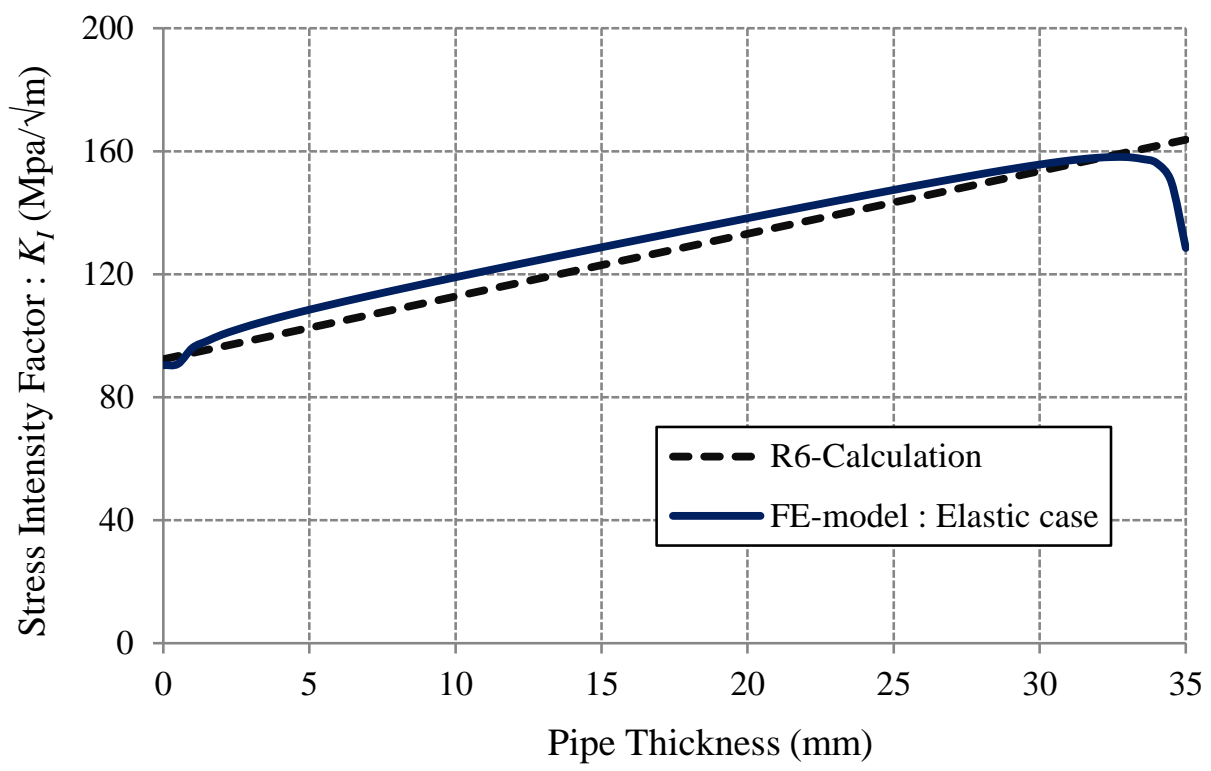

Fig. 9 Comparison between R6-Calculation and elastic FE-results for $K_{I}$ at a bending moment of $230 \mathrm{kN}-\mathrm{m}$.

\section{Residual stress mapping for FE model}

\subsection{Measured residual stresses}

The measured residual stress profiles were obtained from deep-hole drilling technique measurement on a similarly prepared "sister" pipe-weld specimen. The measurement method and the results were described by Do et. Al [33, 34]. Two lines of residual stress measurement were obtained, one along the centre line of the repair weld through the pipe wall thickness, and a second directly opposite to the centre repair weld. In both cases, only the in-plane (i.e. hoop and axial) residual stresses were measured.

\subsection{Residual stresses mapping technique}

Rather than simulate the welding and weld repair process itself, the measured residual stresses were introduced into the mapping zones of the global and the truncated FE-models of the MU2 test, without the crack being present. The mapping zones were defined according to the recommendation of Do and Smith [34], Figure 10. This process was performed via ABAQUS user-defined subroutine named SIGINI.

The residual stress fields in hoop and axial direction were introduced into the FE models as initial stresses. After that an equilibrium step (static step with no additional load applied) was performed in order to generate stress in other components. This step lead to a difference between the initial stress input and the equilibrium residual stress obtained. To minimise this difference, an iterative method [17] was used to modify the input values of initial stress until the equilibrated stress state reproduced the measured residual stress distribution. 


\subsection{Mapped stress}

Figure 11 shows the converged residual stress profiles after applying the iterative technique compared with the measure stress levels. This was achieved after 16 and 21 iterations for the global and truncated FE models respectively. The output stresses in both hoop and axial direction along the repair path agree to within $5 \%$ of the measured values.

The output hoop stress also agreed with the measured value opposite the weld repair except in the region between the inner pipe surface and $17 \mathrm{~mm}(\mathrm{r}=70 \mathrm{~mm})$ from the inner pipe surface. The maximum difference between the mapped and measured hoop stress in this region was $34 \mathrm{MPa}$.

The overall agreement between mapped and measured axial stress in the pipe opposite the repair path was not as good. The difference between mapped and measured values was about $86 \mathrm{MPa}$ at the inner surface, increasing slightly to $89 \mathrm{MPa}$ near the mid thickness of the pipe and was decreased to about $34 \mathrm{MPa}$ at the outer pipe surface.

The converged residual stresses were then mapped directly onto the cracked truncated model for subsequent simulation of the MU2-test.

Figure 11 also shows that in the central region of crack plane, the level of stress triaxiality is reasonably uniform in a direction parallel to crack front, except in the areas adjacent to the inner and outer surfaces. This information supports the assumption that in the simulation of MU2 test using Rousselier damage model, the dimension of the elements ahead of the crack front can be extended from 50 to be $200 \mu \mathrm{m}$ in the direction parallel to the crack front without any significant effect on the results.

\subsection{The redistribution of residual stress in truncated FE model containing the crack}

Figure 12a shows a contour plot of stress triaxiality defined as the ratio of mean stress to von Mises equivalent stress $\left(\sigma_{m} / q\right)$ on the cracked plane following the redistribution of residual stresses due to the introduction of the crack. It shows that in the area ahead of the crack front, the level of stress triaxiality is predicated to be very high in the central region of the crack plane. This is because the stress state in this region is under plane strain conditions. On the other hand, in the area near the free surfaces, the stress triaxiality is predicted to be lower because a state of plane stress dominates in this region.

Figure $12 \mathrm{~b}$ shows the distribution of equivalent plastic strain at the crack tip following it's introduction into the residual stress field. The resulting plastic strain is relatively uniform along the crack front, though there is some evidence of slightly higher, and more widespread plasticity towards the outer edge of the specimen.

As ductile crack growth is highly influenced by the level of stress triaxiality and plastic strain ahead of the crack front, the initiation of crack growth and the maximum extent of crack growth can be predicted to occur in the central region of the crack plane towards the outer surface. 

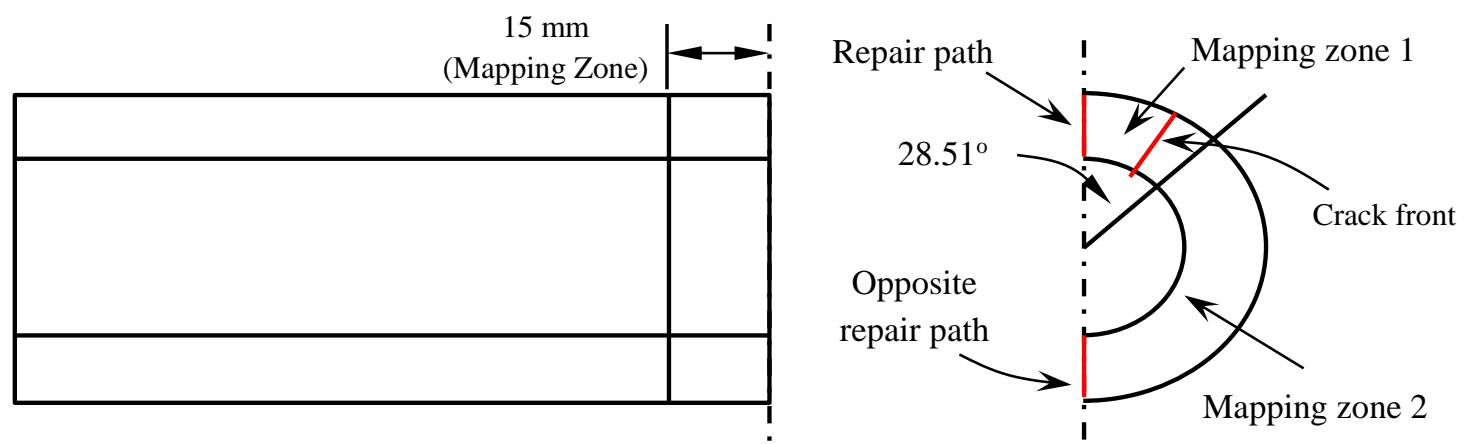

Fig. 10 The location of two lines of residual stress measurement and mapping zones for the FE model [34].
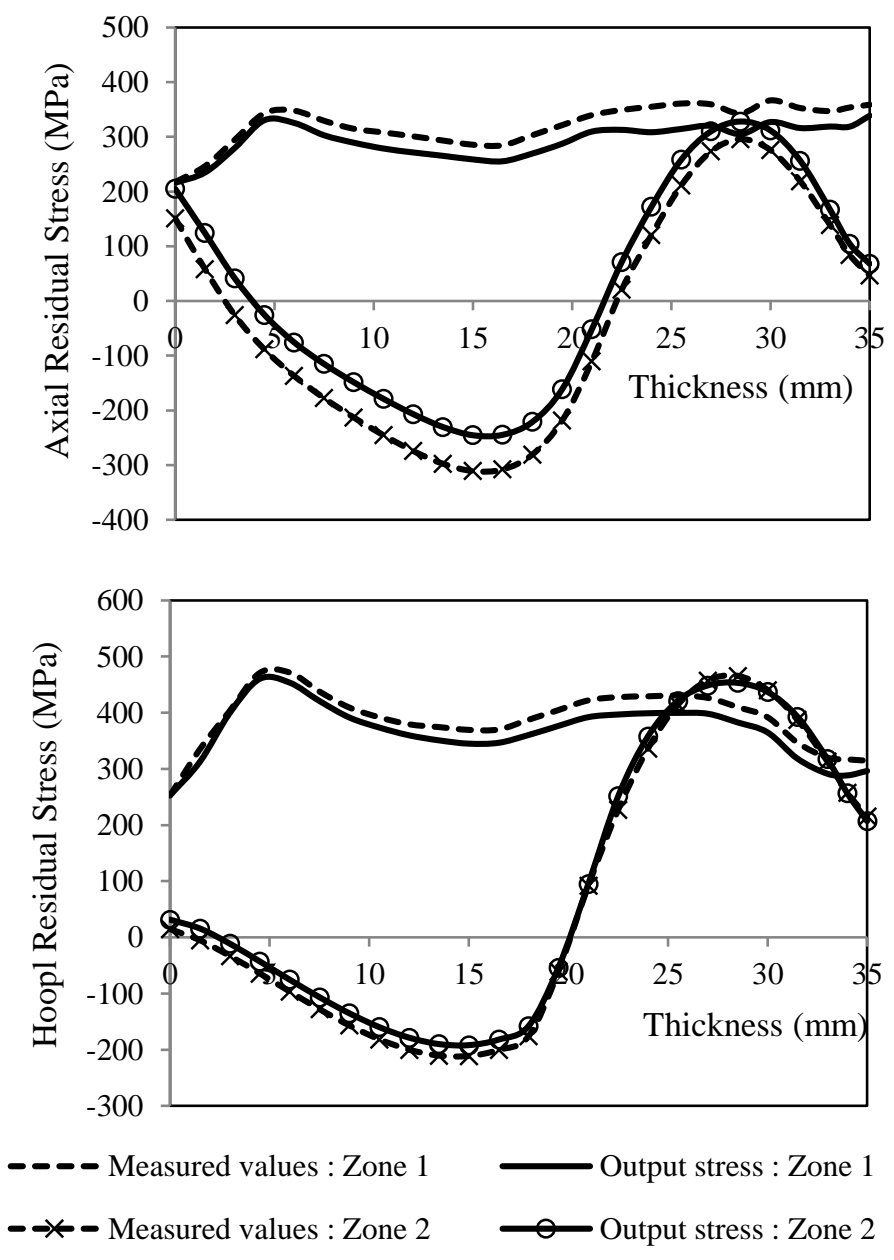

Fig. 11 The measured stress and their corresponding iterated values from the FE model after an equilibrium step. 

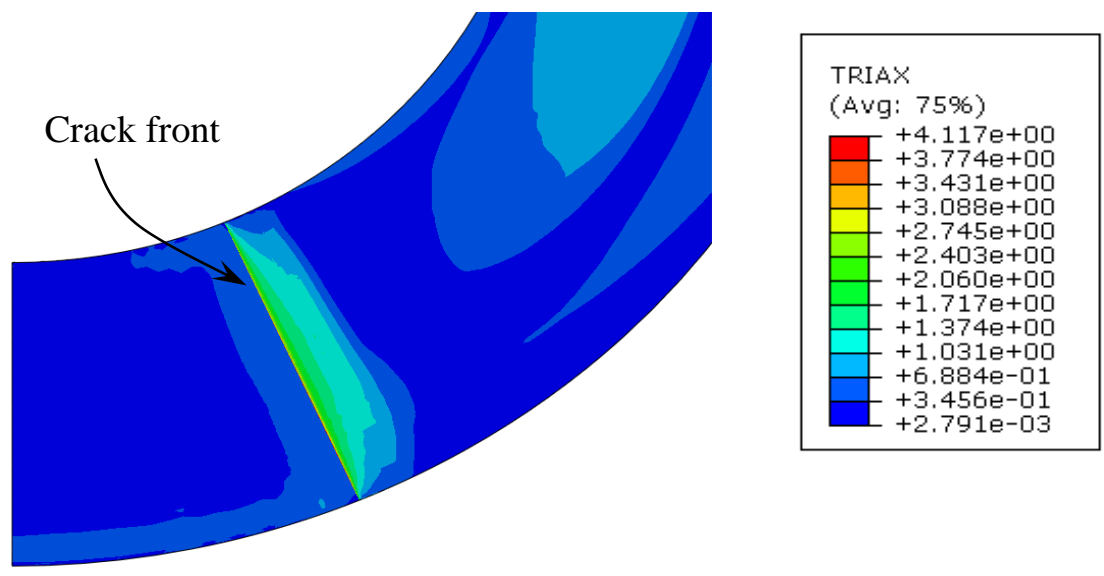

(a)

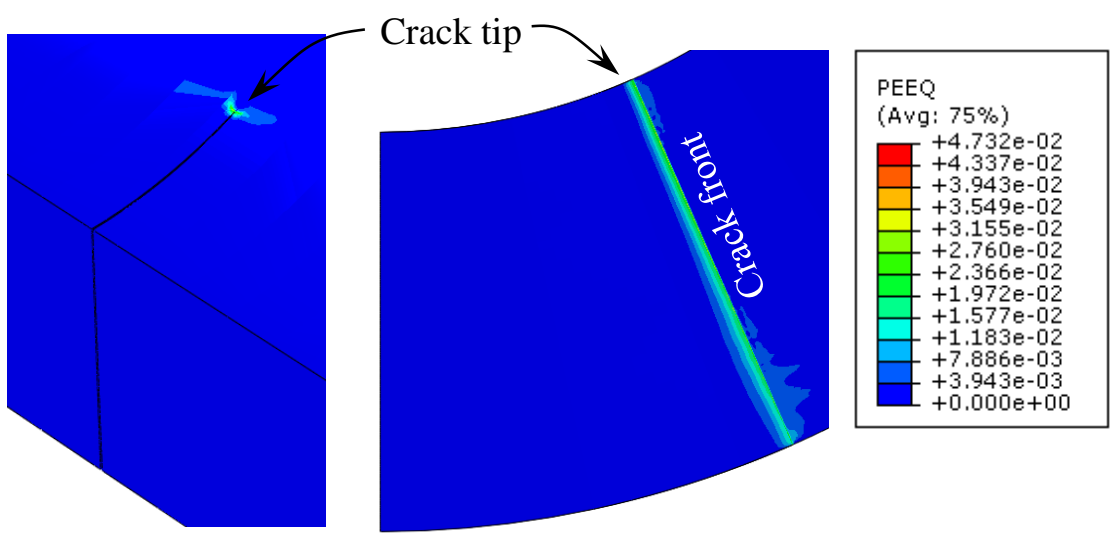

(b)

Fig. 12 The contour plot of (a) stress triaxiality and (b) equivalent plastic strain on the crack plane and surface after the redistribution of residual stresses due to the introduction of crack.

\section{Results and discussion}

\subsection{The global behaviour}

The global FE model of the MU2 test was run with and without the residual stress. The relationship between the applied load and CMOD measured in the test is compared with the FE prediction in Fig. 13. It was found that when the residual stresses were not present, nonlinear behaviour initiated at an applied load of approximately $85 \mathrm{kN}$, whereas with the residual stresses, the non-linear behaviour occurred as soon as the pipe was subjected to external loading. The reason for this behaviour is that the residual stress had already produced plastic tensile strain around the crack front prior to any primary load being applied, Figure 11b.

The relationship between load and CMOD obtain from the global FE model containing the residual stress is in close agreement with the experiment up to the value of CMOD of $0.4 \mathrm{~mm}$. Within this region, CMOD $\leq 0.4 \mathrm{~mm}$, the difference of reaction force obtained from FE-results and experiment is less than $9 \%$. 
For CMOD $>0.4 \mathrm{~mm}$, the reaction force obtained from FE model containing the residual stress is higher than the experimentally measured load by approximately $7 \%$. This may result from a number of limitations in the analysis. Firstly, there was crack propagation during the test, whereas the global FE model was run with a single crack size; crack extension will reduce the applied load at a given value of CMOD, bringing the FEA and experimental data closer together. Secondly, the material properties in the heat affected zone at the weld and the weld repair were not taken into account in this simulation. Thirdly, the model did not consider any influence of residual stresses at the welds joining the MU-test section to the extension arms. Finally, there is some evidence of a discrepancy between the tensile data referenced in this analysis and data obtained in a parallel test programme [19].

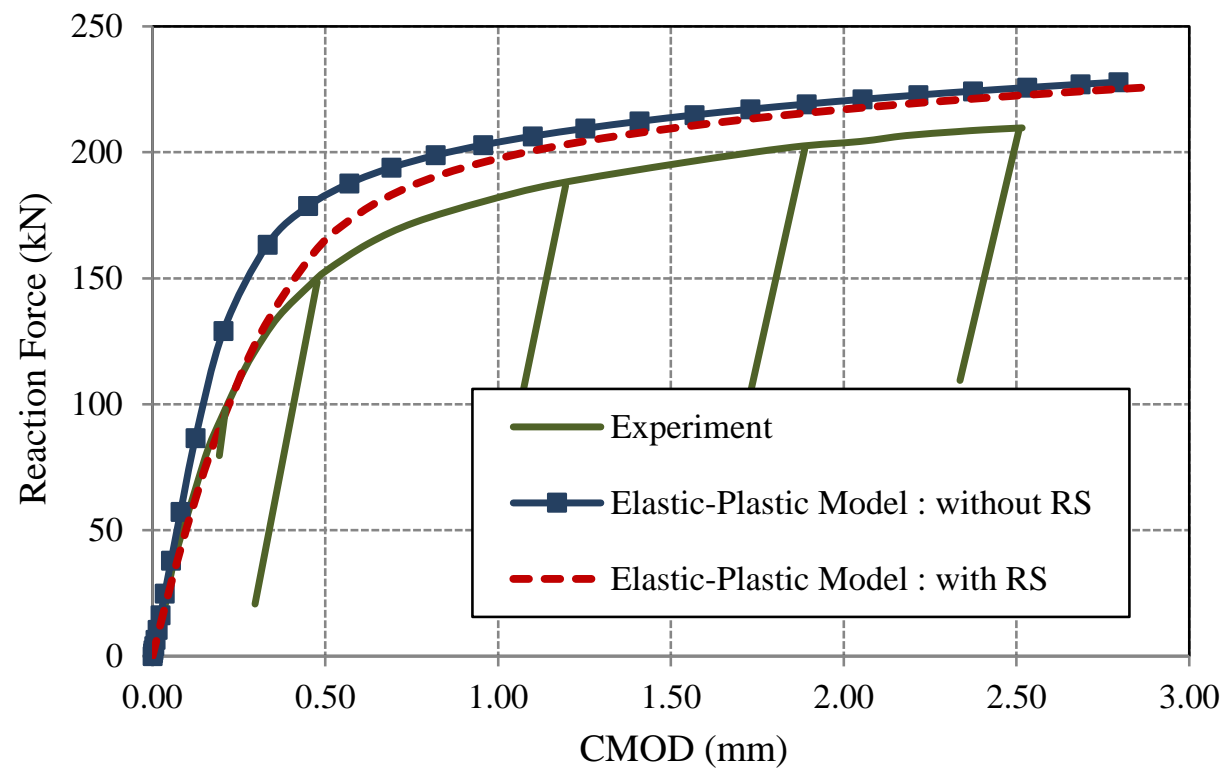

Fig. 13 Acomparison of CMOD versus reaction force between experiment and FE models at full scale CMOD.

\subsection{The FE analysis of the truncated model}

\subsubsection{The prediction of $J$-integral}

The truncated FE model with and without the residual stresses was run using only isotropic hardening data, without the application of the Rouselier constitutive equation. The purpose of this analysis is to investigate the variation of $J$-integral along the crack front at CMOD of 2.5 $\mathrm{mm}$, i.e. the final state of the test. The results of this analysis were presented in Figure 14. It was found that the location of the maximum value of $J$ is at $82 \mathrm{~mm}$ from the inner wall, and the $J$-integral values are higher by about $11 \%$ after introducing the residual stress to the model. These values were subsequently used to estimate the amount of stable crack extension along the crack front in the final state of the test with reference to the $J-R$ curve of the weld, Fig. 6 . The results from this estimation are present in Fig. 15. with the maximum value of stable crack growth of $2.3 \mathrm{~mm}$. This value is close to the test result (in south direction), Fig. 4. 


\subsubsection{Rousselier damage model}

The truncated FE model for MU2 test containing the residual stress was rerun in ABAQUS/Explicit with VUMAT for the Rousselier damage model incorporated in the model for the analysis. This analysis was performed using the Rousslier parameters presented in Section 4 of this paper. The results from this analysis which incorporated the influence of both primary loading on the test specimen and residual stresses at the repair weld are as described below:

- Crack initiation

Crack initiation and propagation in the MU2 specimen were predicted from the failure of elements occurring on the crack plane of the truncated FE model. A part of the FE model ahead of the crack front, where the crack was expected to initiate, was examined in greater detail. The crack initiation position, defined by the failure of the first element ahead the crack front, was predicted to be located between $21 \mathrm{~mm}$ to $28 \mathrm{~mm}$ from the inner pipe surface (i.e. $\mathrm{r}=76-83$ $\mathrm{mm}$ ). This crack initiation corresponded with a value of CMOD equal to $0.073 \mathrm{~mm}$ and bending moment of approximately $37 \mathrm{kN}-\mathrm{m}$.

- Crack propagation

The predicted crack propagation profile is presented in Fig. 16. It can be seen that the crack extended from the crack initiation position in a direction normal to the crack front. As the high stress triaxiality existed in the region between $21-28 \mathrm{~mm}$ (Fig. 12) from the inner pipe surface, the crack extended more rapidly in this region. In the regions adjacent to the inner and outer surfaces, the crack extended more slowly because these were within the low stress triaxiality zone.

The actual crack growth observed in the test was either between 2.0 and $2.5 \mathrm{~mm}$, observed on the south crack tip, and $3.0 \mathrm{~mm}$ observed at the north crack tip at the final applied load in the test, Fig. 4. The predicted amount of crack extension and final crack shape derived from the analyses at a final displacement corresponding to CMOD $=2.5 \mathrm{~mm}$ is shown in Fig. 15. The Rousselier damage model provided a lower prediction of the maximum crack growth when compared with the results obtained using fracture mechanics based on the $J$-integral. The maximum crack extension estimated by Rousselier model was about $2.1 \mathrm{~mm}$ and occurred between 20.3 and $25.3 \mathrm{~mm}$ from the inner pipe surface $(\mathrm{r} \sim 75-80 \mathrm{~mm})$. The equivalent prediction using $J$-integral provided a maximum values of crack extension of $2.3 \mathrm{~mm}$ at $27 \mathrm{~mm}$ $(\mathrm{r}=82 \mathrm{~mm})$ from the inner pipe surface. Thus, the analyses agreed well with the amount of crack extension observed at the south crack tip, but slightly under-predicted the amount of tearing at the north crack tip.

Any modest differences between the predicted and actual amount of ductile tearing observed in the test are likely to result from a combination of three main factors. First, the geometry and/or the loading of the MU-2 test specimen may not have been precisely symmetric as was assumed to be the case in the FE model. Using an average crack growth in the test of $2.5 \mathrm{~mm}$, taken from the minimum and maximum amounts of tearing observed at the north and south crack tips, the fracture mechanics and Rousselier analyses under-predicted the amount of ductile tearing by just $8 \%$ and $16 \%$, respectively. Secondly, the level of residual stress in the region of the crack may have been rather higher than that measured in the "sister" weld 
resulting in a lower crack driving force being predicted by the FE model than was experienced in the test for a given applied displacement. Scatter in measured and predicted residual stresses in welds is well known and described by Leggatt [35] and this will influence the secondary crack driving force [8]. Thirdly, the test weld may have had a lower level of fracture toughness compared with that measured on the "sister" weld and referenced in these analyses. O'Donnell et al. [36] assessed the scatter in fracture toughness properties of wrought and welded stainless steel indicating considerable scatter in the J R-curve of each, though greater scatter was observed in weld metal. Given these considerations, both the Rousselier and the fracture mechanics approaches predicted a similar amount of ductile tearing to the average amount of crack extension observed between each crack tip in the MU-2 test. These considerations also highlight further analyses that could be undertaken to investigate the significance of residual stress and material property variations on the prediction of ductile crack growth using the Rousselier model or fracture mechanics approaches.

Both the Rousselier and the fracture mechanics approaches predicted similar final crack shapes, with the position of maximum tearing corresponding well to that observed in the test at the south crack tip, Fig. 4.

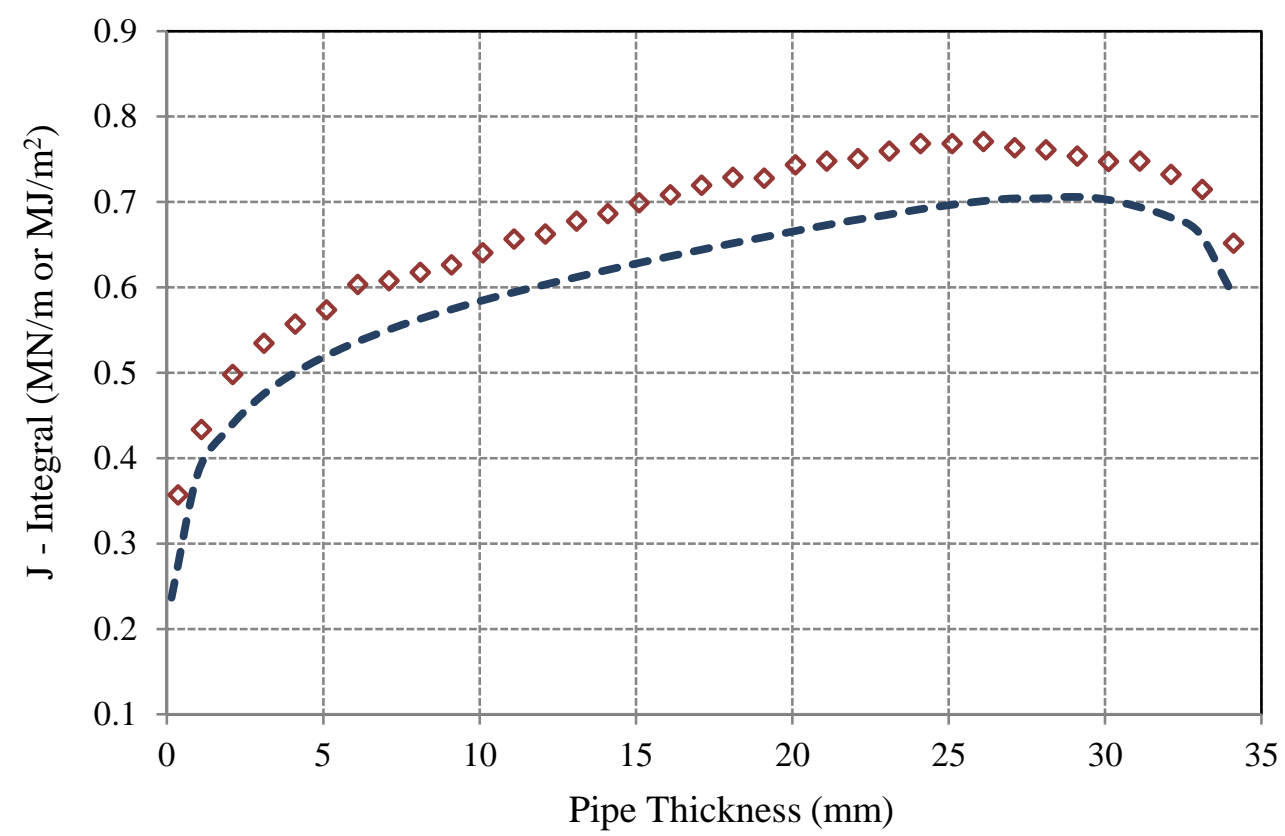

- o Turncated model : Elastic Plastic

$\diamond \quad$ Turncated model : Elastic Plastic with RS

Fig. 14 Comparison of J-integral along the crack front (pipe radius) at CMOD of $2.5 \mathrm{~mm}$. 


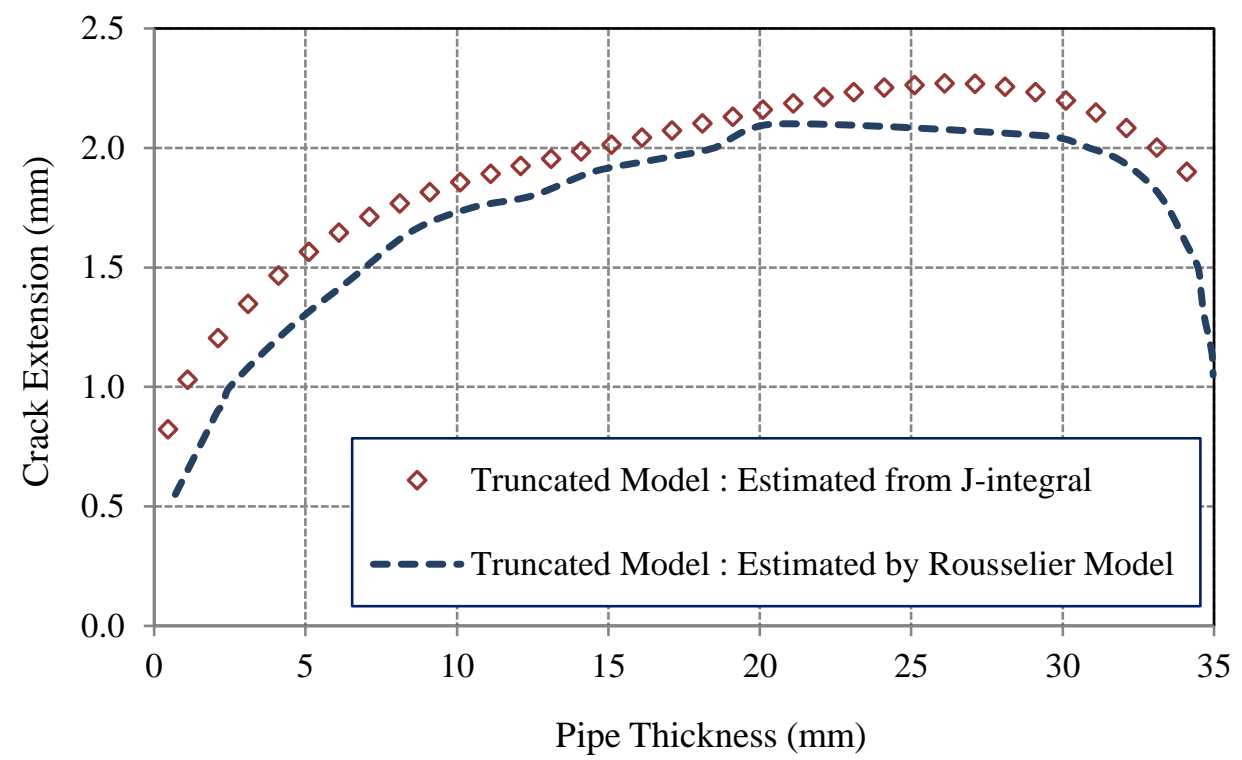

Fig. 15 Estimation of stable crack growth along the crack front (pipe radius) in the final state of the test $(\mathrm{CMOD}=2.5 \mathrm{~mm})$.

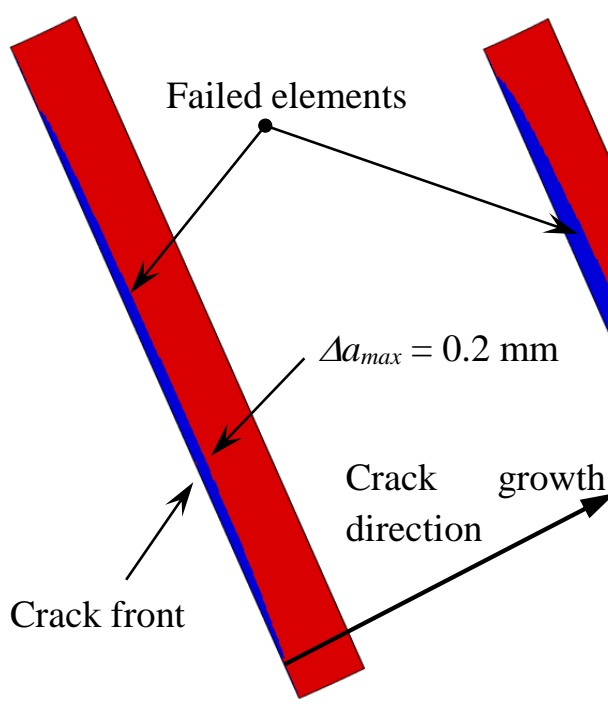

(a)

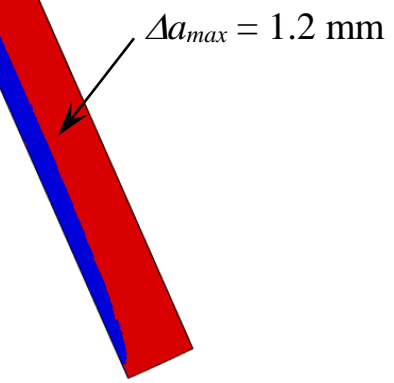

(b)

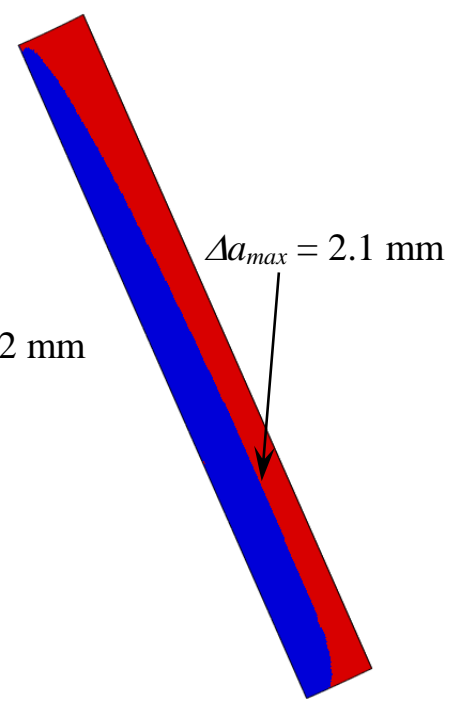

(c)

Fig. 16.The crack propagation profiles : (a) at CMOD of $1.2 \mathrm{~mm}$, (b) at CMOD of $2.0 \mathrm{~mm}$ and (c) at CMOD of $2.5 \mathrm{~mm}$ (final stage of the test).

\section{Summary}

This paper presented a detailed FE simulation that incorporated the influence of both primary load and weld residual stress on ductile tearing in the MU2 welded pipe test undertaken within the STYLE project. In this analysis, the Rousselier damage model was employed to predict the crack initiation position and load, crack propagation profiles and final crack growth of the test 
specimen. In the construction of the FE model of the MU2-test, a submodelling technique was employed in order to study the area of interest in detail. The results obtained from this analysis were compared with the results obtained from the prediction of $J$-integral. The following conclusion are drawn:

- The Rousselier model predicted the location of crack initiation in the region between $21 \mathrm{~mm}$ and $28 \mathrm{~mm}$ from the inner pipe surface at an initiation load of $\sim 37 \mathrm{kN}-\mathrm{m}$.

- The maximum extension of crack predicted by the Rousselier model was $2.1 \mathrm{~mm}$ and occurred between $\sim 20 \mathrm{~mm}$ and $25 \mathrm{~mm}$ from the inner pipe surface. The values of $J$ integral predicted a maximum of crack extension of $\sim 2.3 \mathrm{~mm}$ at $26 \mathrm{~mm}$ from the inner pipe surface.

- The Rousselier model and fracture mechanics approach predicted a similar amount of ductile tearing to the average amount of crack extension observed between each crack tip in the MU-2 test.

- The Rousselier damage model predicted a similar final crack shape which corresponded closely to the prediction of $J$-integral and that observed in the test at the south crack tip.

Overall, the results obtained from this work agree well with the results obtain from the prediction of $J$-integral and the test. This indicates that the FE procedure used in this paper can be considered as a valid engineering tool to predict ductile failure crack growth behaviour in welded structural component. However, the significance of any variations in geometry, loading, residual stress levels and material properties should be explored when using the approach to predict ductile tearing in other applications.

\section{Acknowledgements}

The authors would like to acknowledge the EU-STYLE project (Agreement 249648) for the financial support for this work. We would also like to acknowledge the support provided by EDF-Energy. The large scale experimental test was conducted at the SEMT/LISN laboratory at CEA, Saclay, France, and we are grateful for their contribution. Our special thanks also go to Professor David Smith and Son Do from University of Britol for their contribution on to the residual stress measurement and simulation activities. Finally, we would like to thank Dr.Peter James and Mike Ford from AMEC for their assistance in the finite element modelling and fracture tests respectively. 


\section{References}

1. P.J.Bouchard, Validated residual stress profiles for fracture assessments of stainless steel pipe girth welds. International Journal of Pressure Vessels and Piping, vol.84(4), pp.195-222, 2007.

2. D.George and D.J.Smith, "Through thickness measurement of residual stresses in a stainless steel cylinder containing shallow and deep weld repairs," International Journal of Pressure Vessels and Piping, vol.82(4), pp.279-287, 2005.

3. P.J.Bouchard, D.George, J.R.Santisteban, G.Bruno, M.Dutta, L.Edwards, E.Kingston and D.J.Smith, "Measurement of the residual stresses in a stainless steel pipe girth weld containing long and short repairs," International Journal of Pressure Vessels and Piping, vol.82(4), pp.299-310, 2005.

4. X.B. Ren, Z.L. Zhang, and B. Nyhus, "Effect of residual stresses on the crack-tip constraint in a modified boundary layer model," International Journal of Solids and Structures, 2009. 46(13): p. 2629-2641.

5. Ren, X.B., Z.L. Zhang, and B. Nyhus, "Effect of residual stresses on ductile crack growth resistance," Engineering Fracture Mechanics, 2010. 77(8): p. 1325-1337.

6. API RP 579-1/ASME FFS-1, Fitness-for-service, $2^{\text {nd }}$ Edition, American Petroleum Institute, 2007.

7. BS 7910, Guide to methods for assessing the acceptability of flaws in metallic structures, British Standard Institution, UK, 2013

8. R6: assessment of the integrity of structures containing defects, Revision 4, British Energy Generation Limited, 2005.

9. Z.Q. Lei, J. Chen, F.X. Wang, W.B. Xuan, T. Wang and H. Yang, "Full-scale burst test and finite element simulation of 32 inch oil pipe with girth weld defects", Procedia Engineering, vol.130, pp.911-917, 2015

10. T. Swankie, V. Chauha, R. Espiner, M. Kieba, I. Wood and S. Quong, "Evaluation of girth weld defect acceptance criteria for Grade X100 pipelines", in Proceedings $9^{\text {th }}$ Int. Pipeline Conf. IPC2012, Alberta, Canada, Paper No. IPC2012-90404, Sept. 24-28, 2012

11. J. Dybwad, E. Østby, R. Törnqvist and C. Thaulow, "Simulations of ductile tearing at large strains of biaxially loaded pipes", Proc. ASME $28^{\text {th }}$ Int. Conf. on Ocean, Offshore and Arctic Engineering OMAE2009, Hawaii, USA, Paper No. OMAE2009-79631, June 2009.

12. A.L. Gurson, "Continuum Theory of Ductile Rupture by Void Nucleation and Growth: Part 1-Yield Criteria and Flow Rules for Porous Ductile Media," Journal of Engineering Materials and Technology, vol. 99, pp.2-15, 1977]

13. V. Tvergaard, A. Needleman, "Analysis of the cup- cone fracture in a round tensile bar," Acta Metallurgica 32, pp.157-169, 1984

14. A. Kane and E. Østby, "3D fracture simulations of SENT specimens including welding residual stresses," Proc. ASME $31^{\text {st }}$ Int. Conf. on Ocean, Offshore and Arctic Engineering OMAE2012, Rio de Janeiro, Brazil, Paper No. OMAE2012-84057, July 2012.

15. M.C.Smith, M.Bourgeois, S.Arun, S.D.Cao, Y.Kayser, D.Smith and A.Sherry, "Understanding the impact of high-magnitude repair-weld residual stresses on ductile crack initiation and growth-the STYLE mock up 2 large scale test," in Proceedings of the ASME 2014 Pressure Vessels \& Piping Conference, California, USA, 2014.

16. M.Bourgeois, "Mock-Up 2 Test," STYLE report D-1.15, CEA, France, 2014.

17. Y.Lei, N.P.O'Dowd and G.A.Webster, "Fracture mechanics analysis of a crack in a residual stress field," International Journal of Fracture, vol.106(3), pp.195-216, 2000. 
18. EDF Energy tensile test report, specimen ID 10049-8. date 21/02/2013.

19. M.C.Smith, "Materials characterisation to support the MU2 large scale test," STYLE report, 2014.

20. C.Austin and J.P.Hayes, "A Constitutive Model for Parent Esshete 1250 and Associated Single Bead Weld Metal," Serco Assurance Report SA/SIA/17261/R01, SERCO, UK, 2005.

21. R.K.Blandford,D.K.Morton, S.D.Snow and T.E.Rahl, "Tensile stress-strain results for 304L and 316L stainless steel plate at temperature," in Proceedings of the ASME 2007 Pressure Vessels \& Piping Conference, Texas, USA, 2007.

22. ESIS P2-92, ESIS procedure for determining the fracture behaviour of materials, European Structural Integrity Society, 1992.

23. B.K.Neale and R.H.Priest, "The Unloading Compliance Method for Crack Length Measurement Using Compact Tension and Precracked Charpy Specimens," ElasticPlastic Fracture Test Methods: The User's Experience, ASTM STP 856, American Society for Testing and Materials, Philadelphia, 1985.

24. N.Aravas, "On the numerical integration of a class of pressure-dependent plasticity models," International Journal for Numerical Methods in Engineering, vol.24(7), pp.1395-1416, 1987.

25. G.Rousselier, Ductile fracture models and their potential in local approach of fracture. Nuclear Engineering and Design, vol.105(1), pp.97-111, 1987.

26. G.Rousselier, J.C.Devaux, G.Mottet and G.Devesa, "A Methodology for Ductile Fracture Analysis Based on Damage Mechanics: An Illustration of A Local Approach of Fracture," Nonlinear Fracture Mechanics Volume II: Elastic-plastic Fracture, pp.332-354, ASTM STP 995, 1989.

27. D.-Z.Sun, D. Siegele, B. Voss and W. Schmitt, "Application of local damage models to the numerical analysis of ductile rupture," Fatigue \& Fracture of Engineering Materials \& Structures, vol.12(3), pp.201-212, 1989

28. ABAQUS verson 6.12 documentation, Dassault Systemes Simulia Crop., Rhode Island, 2012.

29. S.Arun, "Finite element modelling of fracture \& damage in austenitic stainless steel in nuclear power plant," in School of Mechanical, Aerospace and Civil Engineering, 2015, the University of Manchester, UK.

30. G.Rousselier, "The Rousselier Model for Porous Metal Plasticity and Ductile Fracture," Handbook of Materials Behavior Models Volume II: Failure of Materials, pp.436-445, CA: Academic Press, 2001.

31. A.G.Franklin, "Comparison between a quantitative microscope and chemical methods for assessment of nonmetallic inclusions," Journal of the Iron and Steel Institute (London), vol.207, pp.181-186, 1969.

32. S.Arun, A.H.Sherry, M.Sheikh and M.C.Smith, " Rousselier parameter calibration for Esshete weld metal", in Proceedings of ASME 2015 Pressure Vessel \& Piping Conference, Boston, USA, 2015.

33. S.Do, D.J.Smith and M.C.Smith, "Effect of ageing on residual stresses in welded stainless steel cylinders," in Proceedings of the ASME 2012 Pressure Vessels \& Piping Conference, Toronto, Canada, 2012.

34. S.Do and D.J.Smith, "Simulations of a Large-scale Four Point Bending Experiment; Influence of Residual Stresses from a Repair Weld," Procedia Materials Science, vol.3(0), pp.1599-1605, 2014.

35. R.H.Leggatt, "Residual stresses in welded structures", International Journal of Pressure Vessels and Piping, vol. 85, pp. 144-151, 2008. 
36. I.J.O'Donnell, H.Huthmann and A.A.Tavassoli, "The fracture toughness behaviour of austenitic steels and weld metal including the effects of thermal ageing and irradiation", International Journal of Pressure Vessel and Piping, vol. 65, pp. 209-220, 1996. 